\title{
Special considerations for adolescent athletic and asthmatic patients
}

\author{
This article was published in the following Dove Press journal: \\ Open Access Journal of Sports Medicine \\ 9 January 2013 \\ Number of times this article has been viewed
}

\author{
Jan C Wuestenfeld ${ }^{1,2}$ \\ Bernd Wolfarth ${ }^{1,2}$ \\ 'Department of Preventive and \\ Rehabilitative Sports Medicine, \\ Technical University Munich (TUM), \\ Munich, Germany; ${ }^{2}$ Institute for \\ Applied Training Science (IAT), \\ Leipzig, Germany
}

\begin{abstract}
Asthma is defined as a chronic inflammatory disorder of the airways with bronchial hyperresponsiveness and variable bronchoconstriction, and is one of the most common diseases in childhood and adolescence. Exercise-induced asthma-like symptoms and asthma are also frequently seen in highly trained athletes. Exercise-induced asthma (EIA) and exerciseinduced bronchoconstriction (EIB) are found in $8 \%-10 \%$ of healthy school-aged children and in $35 \%$ of children with asthma. Highly increased ventilation, inhalation of cold, dry air and air pollutants (eg, chlorine) are thought to be important triggers for EIA and EIB. EIA is often experienced concurrently with vocal cord dysfunction, which needs to be considered during the differential diagnosis. The pharmacological treatment of EIA is similar to the treatment of asthma in nonexercising adolescents. The therapy is based on anti-inflammatory drugs (eg, inhaled glucocorticosteroids) and bronchodilators (eg, $\beta_{2}$-agonists). The treatment of EIB is comparable to the treatment of EIA and leukotriene modifiers offer a new and promising treatment option, particularly in EIB. Generally, athletes may not use $\beta_{2}$-agonists according to the prohibited list of the World Anti-Doping Agency (WADA). However, the WADA list contains specific $\beta_{2}$-agonistic substances that are permitted to be used by inhalation.
\end{abstract}

Keywords: exercise-induced asthma, exercise-induced bronchospasm, adolescents, asthma, athletes

\section{Introduction}

Asthma is defined as a chronic inflammatory disorder of the airways with bronchial hyperresponsiveness and variable bronchoconstriction, and is one of the most common diseases in childhood and adolescence. ${ }^{1}$

Because children are generally physically active and take part in high-intensity exercise, and their physically active lifestyle is widely promoted, it can be deduced that many children will also suffer from asthma. Asthmatic athletes are at increased risk of ventilatory symptom injury through exercise than athletes without asthma. When physical exercise itself is the cause of asthmatic symptoms, the condition is referred to as exercise-induced bronchoconstriction (EIB). ${ }^{2}$ Inherently, when children and adolescents participate in sports, they also have an increased risk of experiencing EIB. However, it is generally accepted that physical activity and sports are beneficial for young asthmatic patients, and given that asthmatic symptoms are well controlled with medication, most young asthmatic athletes are able to perform without restriction, even at elite level.

The focus of this review is to illustrate the different types of exercise-induced ventilatory symptoms, their mechanisms, treatment options, and differential
Correspondence: Jan C Wuestenfeld Institute for Applied Training Science, Marschnerstrasse 29, 04109 Leipzig, Germany

Tel +49 34I 4945265

Fax +49 34I 4945264

Email wuestenfeld@iat.uni-leipzig.de
Open Access Journal of Sports Medicine 20I3:4 I-7

(C) 2013 Wuestenfeld and Wolfarth, publisher and licensee Dove Medical Press Ltd. This is an Open Access Dovepress

http://dx.doi.org// $0.2147 /$ OAJSM.S23438 
diagnosis in adolescent athletes. Treatment side effects and antidoping aspects are also discussed.

To obtain the relevant scientific data, we searched PubMed and Medline for terms such as "exercise-induced asthma" (EIA), "exercise-induced bronchoconstriction", "asthma and child and athlete". Whenever relevant, further references and reviews were included.

In contrast to the fairly rigid medical treatment guidelines for asthmatic adults, it may be appropriate to manage the symptoms of asthma in children and adolescents with more flexibility, depending on their planned physical exercise. Currently, the pharmacological management of asthma and EIB in young athletes is in accordance with the guidelines for the treatment of asthma in nonexercising adolescents, and is primarily based on the administration (through inhalation) of anti-inflammatory drugs (eg, inhaled glucocorticosteroids [ICS]) and bronchodilators (eg, $\beta_{2}$-agonists). Short-acting inhaled $\beta_{2}$-agonists (SABAs) can be used prophylactically prior to exercise or reactively in case of acute bronchoconstriction occurring during exercise or other conditions. Longacting $\beta_{2}$-agonists (LABAs) are often used in combination with ICS as a basic treatment for severe cases. ${ }^{3}$

Although the use of $\beta_{2}$-agonists by athletes is forbidden according to the prohibited list of the World Anti-Doping Agency (WADA), ${ }^{4}$ EIB and asthma in athletes are common and often require the use of inhaled $\beta_{2}$-agonists. Therefore, the WADA list contains specific $\beta_{2}$-agonist substances which are permitted for use by inhalation only. ${ }^{5}$

Differential diagnosis in asthma-like symptoms should further be considered in young athletes with respiratory symptoms. Particularly upper airway obstructions such as vocal cord dysfunction (VCD) have more recently become suspected as triggers for exercise-induced shortness of breath. ${ }^{6,7}$

\section{Epidemiology of asthma and EIB in athletes and adolescent athletes}

Exercised-induced bronchoconstriction and exercise-induced asthma-like symptoms are often diagnosed in highly trained athletes. The prevalence of asthma is higher in elite athletes than in the general population. ${ }^{8}$ The highest reported prevalence for EIB is $45 \%$ in cyclists. ${ }^{9}$ Up to $22 \%$ of Olympic athletes from the United States and Italy (Olympic Games 1996, 1998, and 2000) had asthma. ${ }^{9-12}$ The prevalence of asthma in other highly trained athletes is reported to be between $10 \%$ and $23 \%{ }^{13-15}$ and in adolescent athletes between $12 \%$ and $38 \% .^{16,17}$ The prevalence of EIB is high both in summer and winter sports, but is more common in winter-sport athletes. ${ }^{11,12,18-20}$ Studies show a high prevalence of EIB in cross-country skiers, and other so-called "cold-weatherathletes". ${ }^{21-23}$ Within the "warm-weather athletes", endurance athletes ${ }^{15,24}$ have the highest prevalence, with swimmers and cyclists having the highest proportion of clinically relevant EIB cases. Asthma also seems more common among female athletes, ${ }^{9,12,15}$ but this has not been entirely confirmed. ${ }^{10}$

Exercise-induced asthma (EIA) is found in 8\%-10\% of healthy school-aged children and $35 \%$ in children with asthma. ${ }^{25}$ Furthermore, the degree of EIA in children seems to depend on exercise intensity. A study of children who exercised at $85 \%$ of maximum oxygen uptake $\left(\mathrm{VO}_{2} \max \right)$ showed a fall in forced expiratory volume in one second $\left(\mathrm{FEV}_{1}\right)$ of $8.8 \%$, whereas exercising at $95 \% \mathrm{VO}_{2} \max$ led to a fall in $\mathrm{FEV}_{1}$ by $25.1 \%{ }^{26}$ In addition, the type of training and the type of sport can influence the prevalence of asthma. ${ }^{9-13,15,18,19,24,27-30}$

The prevalence of EIB is reported to be up to $40 \%$ in patients with allergic rhinitis. Therefore, athletes with allergic rhinitis should be tested for EIB even if they only have minor clinical EIB symptoms. ${ }^{31}$

The differentiation of EIA and EIB in the international literature is inconsistent, and many papers do not even differentiate between the two. Carlsen describes two phenotypes of asthma in athletes; the first includes athletes who have had asthma from early childhood, often accompanied by allergic symptoms, the second describes those athletes expressing acute asthmatic symptoms triggered by the exercise stimulus itself. ${ }^{25}$ Although in the second group, traditional asthmatic symptoms may not be obvious, but subjects experience coughing and the release of mucus only after exercise or over prolonged periods of time. These athletes are more likely to suffer from EIB.

\section{Mechanisms of exercised-induced bronchoconstriction}

The mild hyperventilation during exercise and the inhalation of cold, dry air are thought to be important triggers for EIB. ${ }^{32}$ These findings are leading to the development of different etiological theories. One theory concerns the cooling and the other the dehydration of airway epithelial cells, but both result in inflammation of the airway epithelium and airway narrowing. Higher concentrations of inflammatory cells in the sputum of subjects with EIB compared to subjects without EIB have been observed following exercise. ${ }^{33}$ Another mechanism thought to contribute to EIB in elite athletes is minimal airway injury following plasma exudation and cell movement into the airway. Hyperventilation on an injured airway epithelium is believed to dehydrate the airway cells, 
leading to degranulation and the release of inflammatory mediators. ${ }^{34-36}$

The risk of EIB seems to be higher in athletes training more than 20 hours per week compared with athletes training less than 10 hours per week. ${ }^{15}$ Atopic disposition and exposure to pollutants are risk factors for marked exercise-related bronchoconstriction. ${ }^{13,30,37,38}$ Finally, respiratory tract infections were found to increase the bronchial hyperresponsiveness in athletes compared with nonactive subjects during exercise. ${ }^{39}$

The relatively high occurrence of EIB in swimmers ${ }^{24,27,28}$ is interesting and due to issues specific to the sport of swimming. Approximately $36 \%$ of the swimmers in the 2008 German Olympic team had asthmatic symptoms and applied for a therapeutic-use exemption (TUE) to use inhalable $\beta_{2}$-agonists. ${ }^{40}$ One possible reason for the high prevalence of EIB in swimmers is the water in swimming pools, which has chlorine added for disinfection. Inhaling the air floating just above the water surface exposes the swimmers to high concentrations of chlorine. ${ }^{27}$ In athletes with a pre-existing bronchial hyperreactivity, bronchoconstriction is the logical result of chloride gas inhalation. Furthermore, it has been suggested that the repeated exposure to chlorine gas may promote the development of asthma. On the basis of recent studies, ${ }^{41-44}$ it has been suggested that products containing chlorine may provoke an increase in lung-epithelium permeability in susceptible swimmers, increasing the risk of developing EIB.

As with chlorine exposure, other harmful agents in the environment can serve as triggers for airway epithelia injuries. In athletes, performing long bouts of regular exercise up to twice daily with high tidal volumes increases exposure to environmental air pollutants and chemicals compared to sedentary people. Different types of exercises will result in different levels of environmental exposure. For example, cross-country skiers are repeatedly exposed to cold air, ${ }^{45}$ and athletes training and competing on ice (eg, speed skating, ice hockey) may be exposed to nitric oxide as well as to ultrafine particles from resurfacing machines. Athletes training and competing on streets such as cyclists and marathon runners are exposed to traffic air pollution. In addition, many outdoor athletes face exposure to aeroallergens (eg, pollens and moulds) and ozone. One study has shown that participation in sports in regions with high ozone levels led to an increased risk of asthma in children after a 5-year follow up compared to children who were active in areas with lower ozone levels. ${ }^{45}$

\section{Differential diagnosis}

The diagnosis of EIA and EIB can be achieved by standard bronchial provocation or standardized exercise testing (Figure 1). Further differential diagnoses should always

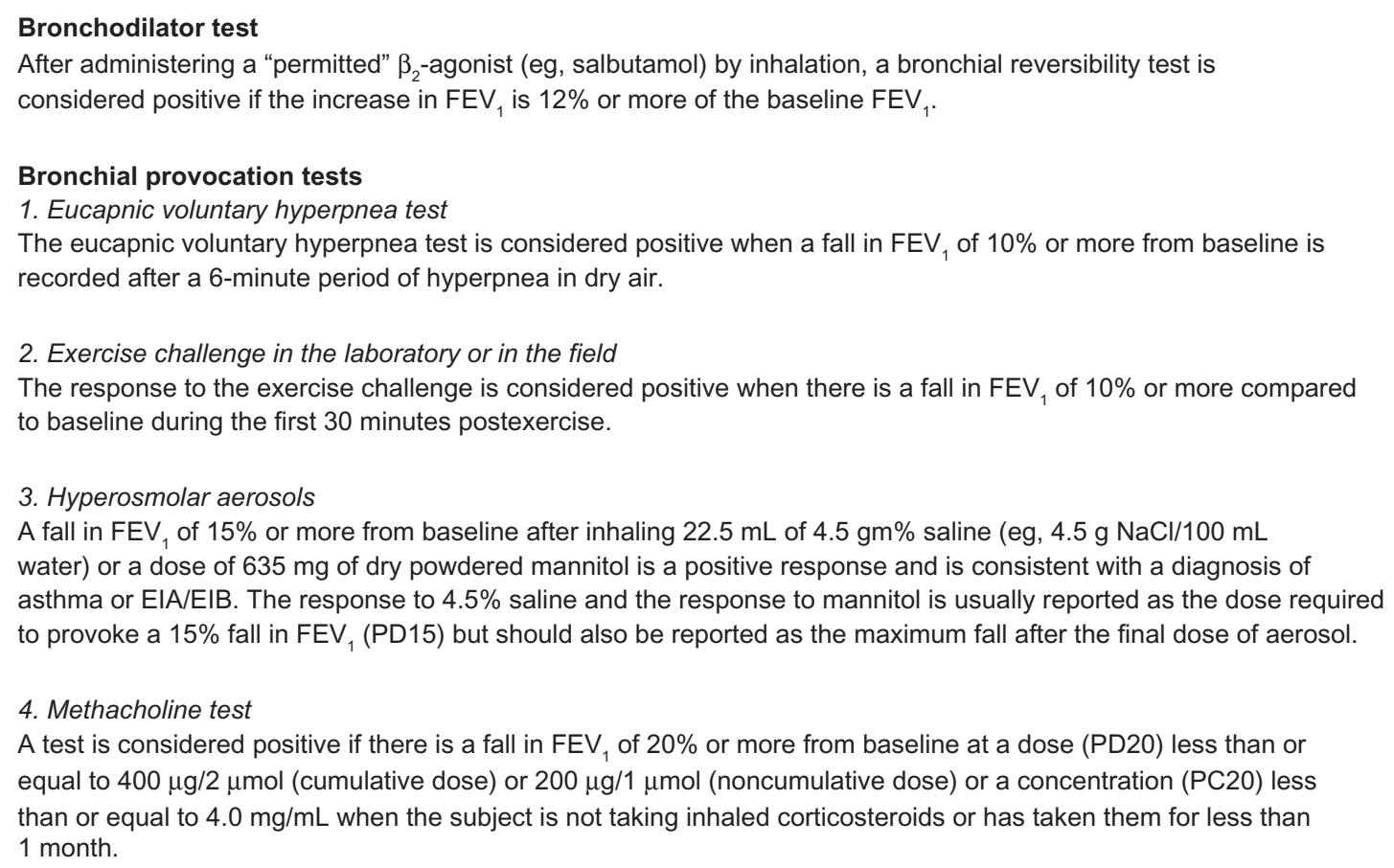

Figure I Diagnosis of EIB/EIA according to IOC Guidelines. ${ }^{81}$

Abbreviations: $\mathrm{FEV}_{1}$, forced expiratory volume in I second; EIB, exercise-induced bronchodilation; ElA, exercise-induced asthma; IOC, International Olympic Committee. 
be considered. Recently it has been shown that EIB coexists and may be confounded by exercise-induced VCD. This observation was first described in adults by Refsum ${ }^{46}$ and later in adolescents by Landwehr et al. ${ }^{47}$ It may occur in $5 \%-27 \%$ of patients primarily diagnosed with EIB. ${ }^{48-51}$ VCD is characterized by a paradoxical closure of the vocal cords during inspiration. It often occurs as noisy breathing, dyspnea, wheezing, coughing, and sensations of obstruction at the level of the upper chest. In a retrospective study of juvenile patients with VCD Powell et al found signs of gastroesophageal reflux disease. A relationship between VCD and psychological stress has also been shown. ${ }^{52}$ Direct visualization of the vocal cords using endoscopy during exercise is the gold standard in diagnosis, but is difficult to obtain. VCD is suspected in the presence of an incomplete or truncated inspiratory loop in the flow-volume curve..$^{53,54}$

The treatment is difficult and many different approaches have been undertaken in the past. ${ }^{53-57} \mathrm{~A}$ consultation with a speech pathologist seems to be indicated, whereas reassurance of the athletes about the non-life-threatening condition by the physician should always be the first step. Further, therapeutic attempts have been described with hypnosis and biofeedback training. Other differential diagnoses, such as chronic respiratory or cardiac conditions, eosinophilic bronchitis, or environmental exposures to toxins are rare, but need to be excluded.

\section{Recommendations for the treatment of EIB in adolescent athletes}

Currently, the treatment of adolescent athletes with EIB is similar to the treatment of adult athletes. ${ }^{3,58,59}$ Baseline therapy is mostly anti-inflammatory, preferably with ICS. In athletes with only rare episodes of EIB, the prophylactical administration of inhaled SABAs may be sufficient. SABAs should be given prior to exercise to prevent attacks of EIB. If athletes use their SABAs more than twice a week, an ICS should be added. In athletes with severe symptoms, a combined therapy with inhaled corticosteroids and LABA is recommended. ${ }^{3,58,59}$

The efficiency of inhaled $\beta_{2}$-agonists has been demonstrated for several substances. ${ }^{60,61}$ The positive effects for LABAs such as salmeterol and formoterol have also been shown. ${ }^{62,63}$ Formoterol has a significant protective effect against EIB compared with placebo.

In a recent review from Ducharme et al it was reported that in asthmatic adults on low and high doses of inhalative corticosteroids as a monotherapy, the addition of a LABA reduced the rate of exacerbations, improved lung function and symptoms, and modestly decreased the need for SABAs. ${ }^{64}$ The effects of this treatment option in children are not known, mainly due to the absence of relevant studies.

Thus far, randomized and controlled studies concerning the effects of other substances such as cromoglycate and nedocromile sodium on EIB in elite athletes have not yet been conducted, although here is some evidence that leukotriene antagonists may help prevent EIB. ${ }^{65-69}$ Due to the links between the development of exercise-induced bronchospasm and the release of inflammatory mediators such as histamine and leukotrienes, leukotriene receptor antagonists and leukotriene synthesis inhibitors have received some interest. ${ }^{70} \mathrm{Of}$ these potential treatments, montelukast is the most studied substance for the control of EIB in patients aged 15 years and older and is considered a useful treatment of EIB. ${ }^{65,70}$

However, in a later review from Ducharme et al for asthmatic adults and children for most asthma measures, inhalative corticosteroids (eg, of $400 \mu \mathrm{g} /$ day of beclomethasone-equivalent) were more effective than antileukotriene agents given in the recommended doses. ${ }^{64,71}$ Still, leukotriene modifiers should remain a treatment option in athletes with EIB in whom therapy with SABA and ICS is insufficient and may be considered before starting therapy with ICS and LABA.

In athletes with an underlying allergic problem, the treatment of allergy symptoms with nonsedating antihistamines and, where appropriate, with nasal steroids should be considered. For athletes in whom allergic exposure plays an important role in their nasal and bronchial symptoms, immunotherapy (hypersensitization) against environmental allergens should be considered. In such cases where subcutaneous immunotherapy with regular injections might be a logistic problem for athletes who travel much, sublingual immunotherapy could be a feasible option.

The treatment of EIB should be followed by regular control visits. Early recognition of exacerbation with appropriate stepping up of medication is important to obtain sufficient disease control.

\section{Relevant side effects of inhaled $\beta_{2}$-agonists}

Athletes can have fatal asthmatic exacerbations during and immediately after participating in sport activities, especially high-intensity training sessions or competition. ${ }^{72}$ Therefore, sufficient diagnosis, prevention, and therapy are necessary. There are however, important and relevant adverse effects of $\beta_{2}$-agonists. The most frequent adverse effects from inhalation of $\beta_{2}$-agonists are tachycardia and muscle fascillation/tremor, 
which are more pronounced in short-acting agents. ${ }^{73}$ Further known adverse effects are headaches and irritability and, at very high doses, hyperglycemia and hypokalemia. ${ }^{73}$ Furthermore, regular administration of $\beta_{2}$-agonists may be associated with the development of tolerance to their effects and increased airway inflammation..$^{63,74-76}$ Tachyphylaxis may develop with both SABAs and LABAs, and the daily use of LABAs attenuates the bronchodilator effect of short-acting substances. ${ }^{74,75,77}$ A combination with inhaled corticosteroids does not necessarily reduce tolerance, but is thought to inhibit this problem.

The development of tolerance to the bronchodilator effects of $\beta_{2}$-agonists could influence the success of rescue therapy in severe EIA/EIB. ${ }^{74-76}$ The increased tolerance is associated with downregulation of peripheral $\beta_{2}$-receptors and desensitization of the receptors. ${ }^{75}$ In addition, tachyphylaxis to $\beta_{2}$-agonists could be modulated by $\beta_{2}$-adrenoceptor gene polymorphisms. ${ }^{78}$

In a review of the problems of inhaled LABAs, ${ }^{79}$ it was concluded that a minor tolerance to bronchodilator activity was seen with formoterol, but not with salmeterol. However, there is a partial loss of protection against EIB with regular use of either of these LABAs. Cardiac risks were not documented. In the same review, it was pointed out that the frequent administration of SABAs induces some loss of bronchodilatation and decrease in bronchoprotective action. Nonetheless, it is accepted that the regular use of ICS and inhaled $\beta_{2}$-agonists is the best current therapy for minimizing chronic damage to the bronchial system related to asthma..$^{58,59}$

\section{Relevant side effects of ICS}

ICS are the most effective medications available for patients with EIB. Nevertheless concerns about potential adverse systemic effects of ICS contribute to their underuse. In an American review the safety of ICS was investigated with respect to potential systemic side effects. ${ }^{80}$ Negative side effects of ICS on the ocular system and on bone mineral density and adrenal function are minimal in patients receiving recommended ICS doses. One-year growth studies in children have shown decreased growth velocity with ICS, but long-term studies on inhaled budesonide and beclomethasone showed no effect on final adult height, suggesting that these effects are transient

\section{World Anti-Doping Code and therapeutic use exemptions}

The so-called prohibited list was first published in 1963 under the leadership of the International Olympic Committee (IOC). Since 2004, as mandated by the World Anti-Doping
Code, WADA is responsible for the preparation and publication of the prohibited list. In the current WADA list all $\beta_{2}$-agonists are prohibited, both in and out of competition. The following exceptions are permitted by inhalation for the prevention and/or treatment of asthma and EIB: formoterol, salbutamol, salmeterol, and terbutaline. A therapeutic use exemption is not needed to justify the use of either ICS or the three $\beta_{2}$-agonists permitted by inhalation. However, all athletes are required to report their $\beta_{2}$-agonist use in the antidoping control form when tested. Further and current information can be found on the WADA website (see http:// www.wada-ama.org). ${ }^{4}$

\section{Summary and conclusion}

Exercise-induced breathing disorders are common in exercising children and adolescents. The underlying mechanism of this disorder is a bronchoconstriction caused by inflammatory processes as a result of hyperventilation on irritated airways. When EIA/EIB is suspected in athletes, a spirometry should follow the extensive medical history and medical examination. Specific objective tests which may confirm the diagnosis, such as standardized exercise tests, metacholine bronchial challenge, or voluntary hyperpnea and mannitol test should follow to confirm the diagnosis. Correct documentation is advised and it is important to comply with the antidoping regulations. If a decision is made to treat with inhaled medications, the only substances should be used are those permitted by WADA.

Regular follow up should be a regular part of disease management to ensure proper and timely therapy adjustment if necessary. The treatment of adolescent EIA and EIB is similar to that of nonathletic asthmatics. Mild forms of EIA may be sufficiently treated with inhaled SABAs, whereas EIB is most likely to be controlled by ICS. The baseline therapy for more severe cases of EIA and EIB is anti-inflammatory with inhaled corticosteroids combined with LABA if necessary. Leukotriene antagonists such as montelukast may provide a feasible alternative or be used in combination, especially in EIB. Differential diagnosis of EIA (eg, VCD) should always be considered especially when treatment with inhalative antiasthmatic agents is ineffective.

In summary, the early diagnosis and anti-inflammatory treatment of EIB in adolescent athletes is necessary to prevent ongoing inflammatory processes in the airway epithelium. A sufficient relief and treatment of these exercise-induced breathing problems further helps to prevent aggravation of EIB and reduce the harmful effects of environmental triggers. Appropriately treated children and adolescents with 
controlled asthma can exercise, train, and compete similarly to their nonasthmatic peers without any limitations.

\section{Acknowledgment}

Thanks are expressed to Jeff Christle who carefully reviewed the paper.

\section{Disclosure}

The authors report no conflicts of interest in this work.

\section{References}

1. Reddel HK, Taylor DR, Bateman ED, et al. An official American Thoracic Society/European Respiratory Society statement: asthma control and exacerbations: standardizing endpoints for clinical asthma trials and clinical practice. Am J Respir Crit Care Med. 2009;180(1):59-99.

2. Carlsen KH, Anderson SD, Bjermer L, et al. Exercise-induced asthma, respiratory and allergic disorders in elite athletes: epidemiology, mechanisms and diagnosis: part I of the report from the Joint Task Force of the European Respiratory Society (ERS) and the European Academy of Allergy and Clinical Immunology (EAACI) in cooperation with GA2LEN. Allergy. 2008;63(4):387-403.

3. Carlsen KH, Anderson SD, Bjermer L, et al. Treatment of exerciseinduced asthma, respiratory and allergic disorders in sports and the relationship to doping: Part II of the report from the Joint Task Force of European Respiratory Society (ERS) and European Academy of Allergy and Clinical Immunology (EAACI) in cooperation with GA(2)LEN. Allergy. 2008;63(5):492-505.

4. World Anti-Doping Agency. The prohibited list [online]. 2012. Available from: http://www.wada-ama.org. Accessed on November 1, 2012.

5. Wolfarth B, Wuestenfeld JC, Kindermann W. Ergogenic effects of inhaled beta2-agonists in non-asthmatic athletes. Endocrinol Metab Clin North Am. 2010;39(1):75-87, ix.

6. Al-Alwan A, Kaminsky D. Vocal cord dysfunction in athletes: clinical presentation and review of the literature. Phys Sports Med. 2012;40(2):22-27.

7. Rhodes RK. Diagnosing vocal cord dysfunction in young athletes. J Am Acad Nurse Pract. 2008;20(12):608-613.

8. Rundell KW, Jenkinson DM. Exercise-induced bronchospasm in the elite athlete. Sports Med. 2002;32(9):583-600.

9. Weiler JM, Layton T, Hunt M. Asthma in United States Olympic athletes who participated in the 1996 Summer Games. J Allergy Clin Immunol. 1998;102(5):722-726.

10. Maiolo C, Fuso L, Todaro A, et al. Prevalence of asthma and atopy in Italian Olympic athletes. Int J Sports Med. 2004;25(2):139-144.

11. Weiler JM, Ryan EJ III. Asthma in United States Olympic athletes who participated in the 1998 Olympic winter games. JAllergy Clin Immunol. 2000;106(2):267-271.

12. Wilber RL, Rundell KW, Szmedra L, Jenkinson DM, Im J, Drake SD. Incidence of exercise-induced bronchospasm in Olympic winter sport athletes. Med Sci Sports Exerc. 2000;32(4):732-737.

13. Helenius IJ, Tikkanen HO, Sarna S, Haahtela T. Asthma and increased bronchial responsiveness in elite athletes: atopy and sport event as risk factors. J Allergy Clin Immunol. 1998;101(5):646-652.

14. Langdeau JB, Turcotte H, Thibault G, Boulet LP. Comparative prevalence of asthma in different groups of athletes: a survey. Can Respir J. 2004;11(6):402-406.

15. Nystad W, Harris J, Borgen JS. Asthma and wheezing among Norwegian elite athletes. Med Sci Sports Exerc. 2000;32(2):266-270.

16. Mannix ET, Roberts MA, Dukes HJ, Magnes CJ, Farber MO. Airways hyperresponsiveness in high school athletes. J Asthma. 2004;41(5):567-574.

17. Rupp NT, Guill MF, Brudno DS. Unrecognized exercise-induced bronchospasm in adolescent athletes. Am J Dis Child. 1992;146(8):941-944.
18. Larsson K, Ohlsen P, Larsson L, Malmberg P, Rydstrom PO, Ulriksen $\mathrm{H}$. High prevalence of asthma in cross country skiers. $B M J$. 1993;307(6915):1326-1329.

19. Sue-Chu M, Larsson L, Bjermer L. Prevalence of asthma in young crosscountry skiers in central Scandinavia: differences between Norway and Sweden. Respir Med. 1996;90(2):99-105.

20. Mannix ET, Farber MO, Palange P, Galassetti P, Manfredi F. Exerciseinduced asthma in figure skaters. Chest. 1996;109(2):312-315.

21. Karjalainen EM, Laitinen A, Sue-Chu M, Altraja A, Bjermer L, Laitinen LA. Evidence of airway inflammation and remodeling in ski athletes with and without bronchial hyperresponsiveness to methacholine. Am J Respir Crit Care Med. 2000;161(6):2086-2091.

22. Helenius IJ, Tikkanen HO, Haahtela T. Occurrence of exercise induced bronchospasm in elite runners: dependence on atopy and exposure to cold air and pollen. Br J Sports Med. 1998;32(2):125-129.

23. Stenfors N. Self-reported symptoms and bronchial hyperresponsiveness in elite cross-country skiers. Respir Med. 2010;104(11): 1760-1763.

24. Helenius I, Haahtela T. Allergy and asthma in elite summer sport athletes. J Allergy Clin Immunol. 2000;106(3):444-452.

25. Carlsen KH. The breathless adolescent asthmatic athlete. Eur Respir J. 2011;38(3):713-720.

26. Carlsen KH, Engh G, Mork M. Exercise-induced bronchoconstriction depends on exercise load. Respir Med. 2000;94(8):750-755.

27. Drobnic F, Freixa A, Casan P, Sanchis J, Guardino X. Assessment of chlorine exposure in swimmers during training. Med Sci Sports Exerc. 1996;28(2):271-274.

28. Langdeau JB, Boulet LP. Prevalence and mechanisms of development of asthma and airway hyperresponsiveness in athletes. Sports Med. 2001;31(8):601-616.

29. Thole RT, Sallis RE, Rubin AL, Smith GN. Exercise-induced bronchospasm prevalence in collegiate cross-country runners. Med Sci Sports Exerc. 2001;33(10):1641-1646.

30. Tikkanen H, Helenius I. Asthma in runners. BMJ. 1994;309(6961): 1087.

31. Deal EC Jr, McFadden ER Jr, Ingram RH Jr, Breslin FJ, Jaeger JJ. Airway responsiveness to cold air and hyperpnea in normal subjects and in those with hay fever and asthma. Am Rev Respir Dis. 1980; 121(4):621-628.

32. Bougault V, Turmel J, St-Laurent J, Bertrand M, Boulet LP. Asthma, airway inflammation and epithelial damage in swimmers and cold-air athletes. Eur Respir J. 2009;33(4):740-746.

33. Hallstrand TS, Moody MW, Aitken ML, Henderson WR Jr. Airway immunopathology of asthma with exercise-induced bronchoconstriction. J Allergy Clin Immunol. 2005;116(3):586-593.

34. Anderson SD, Kippelen P. Airway injury as a mechanism for exerciseinduced bronchoconstriction in elite athletes. J Allergy Clin Immunol. 2008;122(2):225-235.

35. Hallstrand TS, Moody MW, Wurfel MM, Schwartz LB, Henderson WR Jr, Aitken ML. Inflammatory basis of exercise-induced bronchoconstriction. Am J Respir Crit Care Med. 2005;172(6):679-686.

36. Hallstrand TS. New insights into pathogenesis of exercise-induced bronchoconstriction. Curr Opin Allergy Clin Immunol. 2012;12(1): $42-48$.

37. Rundell KW, Spiering BA, Evans TM, Baumann JM. Baseline lung function, exercise-induced bronchoconstriction, and asthma-like symptoms in elite women ice hockey players. Med Sci Sports Exerc. 2004;36(3):405-410.

38. Pierson WE, Covert DS, Koenig JQ, Namekata T, Kim YS. Implications of air pollution effects on athletic performance. Med Sci Sports Exerc. 1986;18(3):322-327.

39. Heir T, Aanestad G, Carlsen KH, Larsen S. Respiratory tract infection and bronchial responsiveness in elite athletes and sedentary control subjects. Scand J Med Sci Sports. 1995;5(2):94-99.

40. Wolfarth B, Engelhardt M, Eder K, Kindermann W. Sportmedizinische Betreuung bei den Olympischen Spielen 2008. Leistungssport. 2009;39:1-4. 
41. Bernard A, Carbonnelle S, Michel O, et al. Lung hyperpermeability the attendance at indoor chlorinated swimming pools. Occup Environ Med. 2003;60(6):385-394.

42. Bernard A, Nickmilder M, Voisin C. Outdoor swimming pools and the risks of asthma and allergies during adolescence. Eur Respir J. 2008;32(4):979-988.

43. Bernard A, Carbonnelle S, de Burbure C, Michel O, Nickmilder M. Chlorinated pool attendance, atopy, and the risk of asthma during childhood. Environ Health Perspect. 2006;114(10):1567-1573.

44. Lagerkvist BJ, Bernard A, Blomberg A, et al. Pulmonary epithelial integrity in children: relationship to ambient ozone exposure and swimming pool attendance. Environ Health Perspect. 2004;112(17):1768-1771.

45. McConnell R, Berhane K, Gilliland F, et al. Asthma in exercising children exposed to ozone: a cohort study. Lancet. 2002;359(9304):386-391.

46. Refsum HE. Excercise-Associated Ventilatory Insufficiency in Adolescent Athletes. The Asthmatic Child in Play and Sports. London, UK: Pitman Books Limited; 1983.

47. Landwehr LP, Wood RP, Blager FB, Milgrom H. Vocal cord dysfunction mimicking exercise-induced bronchospasm in adolescents. Pediatrics. 1996;98(5):971-974.

48. McFadden ER Jr, Zawadski DK. Vocal cord dysfunction masquerading as exercise-induced asthma. a physiologic cause for "choking" during athletic activities. Am J Respir Crit Care Med. 1996;153(3):942-947.

49. Morris MJ, Deal LE, Bean DR, Grbach VX, Morgan JA. Vocal cord dysfunction in patients with exertional dyspnea. Chest. 1999;116(6): 1676-1682.

50. Sterner JB, Morris MJ, Sill JM, Hayes JA. Inspiratory flow-volume curve evaluation for detecting upper airway disease. Respir Care. 2009; 54(4):461-466.

51. Davis RS, Brugman SM, Larsen GL. Use of videography in the diagnosis of exercise-induced vocal cord dysfunction: a case report with video clips. J Allergy Clin Immunol. 2007;119(6):1329-1331.

52. Powell DM, Karanfilov BI, Beechler KB, Treole K, Trudeau MD, Forrest LA. Paradoxical vocal cord dysfunction in juveniles. Arch Otolaryngol Head Neck Surg. 2000;126(1):29-34.

53. Roksund OD, Maat RC, Heimdal JH, Olofsson J, Skadberg BT, Halvorsen T. Exercise induced dyspnea in the young. Larynx as the bottleneck of the airways. Respir Med. 2009;103(12):1911-1918.

54. Morris MJ, Christopher KL. Difficult-to-treat asthma or vocal cord dysfunction? Am J Respir Crit Care Med. 2012;185(3):340-341.

55. Weir M. Vocal cord dysfunction mimics asthma and may respond to heliox. Clin Pediatr (Phila). 2002;41(1):37-41.

56. Earles J, Kerr B, Kellar M. Psychophysiologic treatment of vocal cord dysfunction. Ann Allergy Asthma Immunol. 2003;90(6):669-671.

57. Wilson JJ, Theis SM, Wilson EM. Evaluation and management of vocal cord dysfunction in the athlete. Curr Sports Med Rep. 2009;8(2):65-70.

58. Kelly HW. What is new with the beta2-agonists: issues in the management of asthma. Ann Pharmacother. 2005;39(5):931-938.

59. Sears MR, Lotvall J. Past, present and future - beta2-adrenoceptor agonists in asthma management. Respir Med. 2005;99(2):152-170.

60. Shapiro GG, Kemp JP, DeJong R, et al. Effects of albuterol and procaterol on exercise-induced asthma. Ann Allergy. 1990;65(4):273-276.

61. Anderson SD, Rodwell LT, Du TJ, Young IH. Duration of protection by inhaled salmeterol in exercise-induced asthma. Chest. 1991;100(5): 1254-1260.

62. Ferrari M, Balestreri F, Baratieri S, Biasin C, Oldani V, Lo Cascio V. Evidence of the rapid protective effect of formoterol dry-powder inhalation against exercise-induced bronchospasm in athletes with asthma. Respiration. 2000;67(5):510-513. and asthma prevalence in schoolchildren: unexpected associations with

63. Nelson JA, Strauss L, Skowronski M, Ciufo R, Novak R, McFadden ER Jr Effect of long-term salmeterol treatment on exercise-induced asthma. N Engl J Med. 1998;339(3):141-146.

64. Ducharme FM, Ni CM, Greenstone I, Lasserson TJ. Addition of long-acting beta2-agonists to inhaled corticosteroids versus same dose inhaled corticosteroids for chronic asthma in adults and children. Cochrane Database Syst Rev. 2010;5:CD005535.

65. Leff JA, Busse WW, Pearlman D, et al. Montelukast, a leukotrienereceptor antagonist, for the treatment of mild asthma and exerciseinduced bronchoconstriction. N Engl J Med. 1998;339(3):147-152.

66. Rundell KW, Spiering BA, Baumann JM, Evans TM. Effects of montelukast on airway narrowing from eucapnic voluntary hyperventilation and cold air exercise. Br J Sports Med. 2005;39(4):232-236.

67. Steinshamn S, Sandsund M, Sue-Chu M, Bjermer L. Effects of montelukast and salmeterol on physical performance and exercise economy in adult asthmatics with exercise-induced bronchoconstriction. Chest. 2004;126(4):1154-1160.

68. Todaro A, Faina M, Alippi B, Dal MA, Ruggieri F. Nedocromil sodium in the prevention of exercise-induced bronchospasm in athletes with asthma. J Sports Med Phys Fitness. 1993;33(2):137-145.

69. Valero A, Garrido E, Malet A, Estruch A, Gispert J, Rubio E. Exerciseinduced asthma prophylaxis in athletes using inhaled nedocromil sodium. Allergol Immunopathol (Madr). 1996;24(2):81-86.

70. Kemp JP. Exercise-induced bronchoconstriction: The effects of montelukast, a leukotriene receptor antagonist. Ther Clin Risk Manag. 2009;5:923-933.

71. Ducharme FM. Inhaled corticosteroids versus leukotriene antagonists as first-line therapy for asthma: a systematic review of current evidence. Treat Respir Med. 2004;3(6):399-405.

72. Becker JM, Rogers J, Rossini G, Mirchandani H, D’Alonzo GE Jr. Asthma deaths during sports: report of a 7-year experience. J Allergy Clin Immunol. 2004;113(2):264-267.

73. Abramson MJ, Walters J, Walters EH. Adverse effects of beta-agonists: are they clinically relevant? Am J Respir Med. 2003;2(4):287-297.

74. Anderson SD, Brannan JD. Long-acting beta 2-adrenoceptor agonists and exercise-induced asthma: lessons to guide us in the future. Paediatr Drugs. 2004;6(3):161-175.

75. Salpeter SR, Ormiston TM, Salpeter EE. Meta-analysis: respiratory tolerance to regular beta2-agonist use in patients with asthma. Ann Intern Med. 2004;140(10):802-813.

76. Anderson SD, Caillaud C, Brannan JD. Beta2-agonists and exerciseinduced asthma. Clin Rev Allergy Immunol. 2006;31(2-3):163-180.

77. Salpeter SR, Buckley NS, Ormiston TM, Salpeter EE. Meta-analysis: effect of long-acting beta-agonists on severe asthma exacerbations and asthma-related deaths. Ann Intern Med. 2006;144(12):904-912.

78. Taylor DR, Drazen JM, Herbison GP, Yandava CN, Hancox RJ, Town GI. Asthma exacerbations during long term beta agonist use: influence of beta(2) adrenoceptor polymorphism. Thorax. 2000;55(9):762-767.

79. Nelson HS. Is there a problem with inhaled long-acting beta-adrenergic agonists? J Allergy Clin Immunol. 2006;117(1):3-16.

80. Allen DB. Effects of inhaled steroids on growth, bone metabolism and adrenal function. Expert Rev Respir Med. 2007;1(1):65-74.

81. International Olympic Comittee (IOC), Beta2 adrenoceptor agonists and the Olympic Games in Bejing. [webpage on internet] 2008, Available from: http://www.olympic.org/Documents/Reports/EN/en_report_1302.pdf

\section{Dovepress}

\section{Publish your work in this journal}

Open Access Journal of Sports Medicine is an international, peer-reviewed, open access journal publishing original research, reports, reviews and commentaries on all areas of sports medicine. The manuscript management system is completely online and includes a very quick and fair peer-review system.
Visit http://www.dovepress.com/testimonials.php to read real quotes from published authors. 